\title{
Multi-Stage Fuzzy-Logic Model for Evaluation of Reshoring Decisions
}

\author{
Movin SEQUEIRA ${ }^{1}$ \\ School of Engineering, Jönköping University, Sweden
}

\begin{abstract}
Reshoring decisions are complex due to multiple groups of criteria that have an impact on the decision involved. In order to support this manual decisionmaking process, more advanced tools need to be developed. The purpose of this paper is to explore a multi-stage fuzzy-logic model to support the reshoring decision-making process through a transdisciplinary approach. Three relevant stages pertaining to reshoring decisions were identified: production resources, production capabilities, and competitive priorities. For each stage, factor loading values were used to create fuzzy rules. The model provides a decision recommendation based on a set of input reshoring scenarios. The research contributes to the reshoring literature providing a multi-stage fuzzy-logic model that simultaneously handles different groups of criteria, and to practitioners by contemplating different key competencies within a company during the reshoring decision process.
\end{abstract}

Keywords. Reshoring, decision support, fuzzy logic, multi-stage, transdisciplinary

\section{Introduction}

Manufacturing companies have increasingly relocated their activities back to their home country, which is known as reshoring [1]. Reshoring decisions are less understood with respect to the decision-making process [2, 3]. Consequently, many authors have indicated that the research on reshoring decision support is of high priority [4]. One reason for the lack of research related to decision support is the complexity that is present in these decisions [5]. Another reason is the presence of too many groups of criteria that have an impact on the decision, challenging managers whether to consider all of the present criteria or only a reduced set consisting of the most important criteria [6]. Yet another possible reason for the lack of research in this area is that these decisions sometimes involve human preconceived notions, which need to be contemplated and avoided, if possible [7]. Consequently, dealing with such complex decisions involving an unmanageable number of criteria that are hard to quantify and measure, as well as a biased management team, requires advanced decision support tools that can handle these issues jointly.

Different kinds of decision support tools or models have been developed to either understand or support reshoring decisions. For instance, system dynamics models provide insights into the heuristics of the managers based on gaps between desired and achieved performance [5]. Other examples are landed-cost models that lead to cost-based reshoring decisions [8]. Both models focus on cost and quality criteria but lack

${ }^{1}$ Corresponding Author, Mail: movin.sequeira@ju.se. 
perspectives on other criteria, for example, time, flexibility, innovation, and sustainability that make up a company's competitive priorities [3].

Fuzzy logic-based tools, that have been applied to a wide range of operations management problems, have been developed for reshoring decisions [9-11], however, these include only one group of criteria, limiting their use to only the initial stages of the reshoring decision-making process. It has been proposed that fuzzy logic-based tools should consider criteria beyond the competitive priorities of a company using a multistage architecture for reshoring decisions [11]. Furthermore, different key persons within the company are the managers who are involved during the reshoring decision-making process, focus on different groups of criteria based on the needs of different organizational functions [12].

Developing decision support for manufacturing reshoring requires a transdisciplinary approach. Reshoring is real life, practice-oriented, and society-relevant problem. The persons involved in reshoring decisions belong to different disciplines [12]. Developing decision support for such problems requires having an open mind to various disciplines and to cross the boundaries spanning the different disciplines, especially engineering and operations management $[15,16]$.

The purpose of this study is to develop a multi-stage fuzzy-logic model to evaluate different reshoring decision scenarios. The need for a multi-stage model is due to the different types of criteria that are considered simultaneously in a reshoring decision. A multi-stage model is suitable when handling the complexities of a large number of criteria $[13,14]$. Furthermore, reshoring is a multi-dimensional decision with trade-offs that need to be balanced between various dimensions [1]. Finally, a fuzzy-logic version of a multi-stage model is appropriate in order to handle the uncertainties present in the criteria. To prove the value of the model and the correctness of the generated results, a set of reshoring alternatives, or scenarios, are applied to the model.

\section{Literature review}

This section reviews the literature on three areas that are relevant for this study: the reshoring decision-making process, the decision-making criteria, and fuzzy-logic decision support for reshoring.

\subsection{Reshoring decision-making process}

Several authors have proposed a generic decision-making process for reshoring. These can be classified into linear and cyclical decision-making processes. The linear reshoring decision-making process comprises five stages of feasibility and further three stages for implementation inspired by the insourcing process [17]. The cyclical reshoring decisionmaking process consists of several loops for feasibility and implementation. There is a lack of clear distinction between the feasibility and the implementation loops, which allows for the decision to be reversed even if the implementation has just started [6]. The cyclical decision-making process indicates the complexities present in the reshoring decision-making process that cannot be captured by the linear decision-making process. 


\subsection{Reshoring decision-making criteria}

The decision criteria are those factors that are considered in the decision-making process [10]. The main criteria are cost, quality, lead times and flexibility $[18,19]$. These criteria correspond to the competitive priorities of the company, as the main objective of any reshoring is to increase the overall competitiveness [3]. Of these criteria, cost and quality are considered most important for reshoring, while sustainability is often considered to be the least important criteria [20].

In order to achieve the desired competitive priorities, the capabilities and resources in the production need to be identified [3], which are considered subsequent criteria (or sub-criteria) to the competitive priorities. Some sub-criteria related to production capabilities, for example, improvements in product or process quality, reduced total costs [19] improved production flexibility [21], and volume flexibility [18] have been investigated and their importance has been communicated through either factor loading values or priority weights.

Sub-criteria pertaining to resources need to be considered in reshoring decisions [4], as resources are either spent or transformed to achieve the desired competitive priority [3]. For example, a resource such as highly skilled labor is required in the home country as the shop floor tasks become automated when reshoring [23]. Furthermore, reshoring projects consider heavy investments in automation technologies and robotics [24]. Reshoring decisions, in some cases, require physical proximity to R\&D functions and industrial clusters for innovation [4]. With increasing emphasis on sustainability, there is a need for more sustainable manufacturing processes [25]. The set of reshoring decision criteria belong to competitive priorities, production capabilities, and production resources are shown in the table (Table 1).

Table 1. Criteria groups in reshoring decisions with their relative importance.

\begin{tabular}{|c|c|c|c|}
\hline Group & Criteria & Relative importance & Source \\
\hline \multirow{6}{*}{$\begin{array}{l}\text { Competitive } \\
\text { priorities }\end{array}$} & Cost & 0.38 & {$[20]$} \\
\hline & Quality & 0.41 & [20] \\
\hline & Time & 0.07 & [20] \\
\hline & Flexibility & 0.07 & {$[20]$} \\
\hline & Innovation & 0.07 & [20] \\
\hline & Sustainability & 0 & {$[20]$} \\
\hline \multirow{4}{*}{$\begin{array}{l}\text { Production } \\
\text { capabilities }\end{array}$} & Process efficiency [Cost] & 0.7425 & [19] \\
\hline & Process quality [Quality] & 0.832 & [19] \\
\hline & Volume flexibility [Flexibility] & 0.55 & [18] \\
\hline & Production mix flexibility [Flexibility] & 0.72 & [21] \\
\hline \multirow{7}{*}{$\begin{array}{l}\text { Production } \\
\text { resources }\end{array}$} & Proximity to R\&D & 0.664 & [26] \\
\hline & Proximity to industrial cluster & 0.02 & [27] \\
\hline & Availability of labor & 0.791 & [19] \\
\hline & Availability of production infrastructure & 0.626 & [28] \\
\hline & Availability of production technology & 0.793 & [19] \\
\hline & Availability of digital technology & 0.14 & [21] \\
\hline & Availability of production capacity & 0.61 & [18] \\
\hline
\end{tabular}

\subsection{Fuzzy-logic decision support for reshoring decisions}

The fuzzy-logic decision support is associated with several degrees of truth values that allow for the expression of linguistic statements like human reasoning [29]. The degrees 
of truth values are known as membership grades where each variable like "bad", "neutral" or "good" is transformed to a truth value from zero to one. Fuzzy-logic decision support consists of four functional blocks, as shown in Figure 1. First, the fuzzification block transforms the input data into fuzzy values. Next, the knowledge block consists of the variable lists, membership functions, and rules. Next, the inference block consists of operations that fire one or more rules from the knowledge block and returns a fuzzy value. Finally, the defuzzification block converts the fuzzy value to an output that is understandable to the user.

Fuzzy-logic decision support has been explored for reshoring decisions [9-11]. To replicate the reasoning of the reshoring experts, three novel concepts were outlined. The first concept, relative labels, provides an intuitive and consistent way of reasoning for the decision-maker. For example, the variables, negative and positive are suggested to be consistent to different stakeholders rather than absolute variables low and high [9]. The second concept is the high-level rules, which consist of a reduced set of rules that are obvious and meaningful for the decision-maker. The high-level rules simplify the rule design process [9]. The third concept is the variable weights in the design of the fuzzy rules. The variable weights facilitate the automatic creation of the fuzzy rules [9], simplifying the design process. Therefore, the fuzzy-logic decision support for reshoring can be designed in two ways: (1) complete rules or (2) reduced set of high-level rules [9, $11]$.

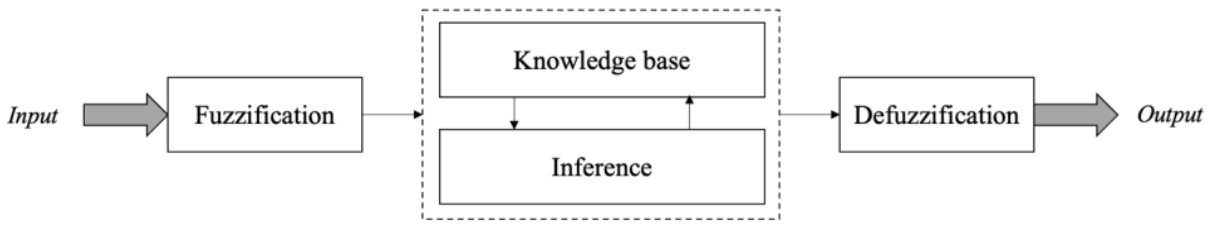

Figure 1. Fuzzy logic system.

\section{Development of multi-stage fuzzy-logic model for reshoring decisions}

A multi-stage fuzzy-logic model is developed based on weights of criteria found in previous research [18-21]. The first stage focus on production resources, the second on production capabilities, and the third one on competitive priorities. The stages are connected in a cascaded manner [13]. The development of each stage follows a stepwise procedure explained in continuation.

\subsection{Define linguistic variables and linguistic labels for each stage}

The linguistic variables are equivalent to the criteria found in the review (Table 1). The relative linguistic labels negative and positive were used for the inputs, both having a Gaussian distribution of membership functions. The range of all of the input variables was defined from $[-10,10]$, where -10 indicates the most negative impact on the variable when reshoring, while 10 indicates the most positive impact on the variable when reshoring. For the output, the linguistic labels Exit and Further evaluate were used, each having a triangular distribution of membership function. 


\subsection{Define variable weights for each stage}

In the second step, variable weights are specified. The weights for the variables are retrieved from factor loading values from existing surveys in the reshoring literature [19, $21,22,26,30]$ as shown in Table 1 . The variable weights obtained from the surveys are then normalized. This is shown in Table 2.

Table 2. Normalized weights of criteria.

\begin{tabular}{lll}
\hline Criteria & Relative importance & Normalized weights \\
\hline Cost & 0.38 & 0.38 \\
Quality & 0.41 & 0.41 \\
Time & 0.07 & 0.07 \\
Flexibility & 0.07 & 0.07 \\
Innovation & 0.07 & 0.07 \\
Sustainability & 0 & 0 \\
\hline Process efficiency [Cost] & 0.7425 & 0.261 \\
Process quality [Quality] & 0.832 & 0.292 \\
Volume flexibility [Flexibility] & 0.55 & 0.193 \\
Production mix flexibility [Flexibility] & 0.72 & 0.253 \\
\hline Proximity to R\&D & 0.664 & 0.182 \\
Proximity to industrial cluster & 0.02 & 0.005 \\
Availability of labor & 0.791 & 0.217 \\
Availability of production infrastructure & 0.626 & 0.171 \\
Availability of production technology & 0.793 & 0.217 \\
Availability of digital technology & 0.14 & 0.038 \\
Availability of production capacity & 0.61 & 0.167 \\
\hline
\end{tabular}

\subsection{Generate fuzzy rules for each stage}

In the third step, the fuzzy rules are generated in an automatic manner applying the normalized variable weights $[9,11]$. The variable weights were assigned to the antecedent part of each fuzzy rule, while the consequent part of each rule was computed in a weighted-sum manner. Therefore, a complete set of rules was generated. For the first stage (i.e., production resources) 128 rules were generated, for the second stage (i.e., production capabilities) 16 rules were generated and for the third stage (i.e., competitive priorities) 64 rules were generated, all in an automatic fashion.

\subsection{Select model parameters for each stage}

In the fourth step, appropriate parameters are specified for each stage of the fuzzy logic model. The parameters $[\mathrm{AND}=\min ; \mathrm{OR}=\max$; Implication $=$ min; Aggregation $=\max$; Defuzzification=mom] was set for each stage based on the best setting reported for fuzzy logic-based reshoring models [11].

\subsection{Combine each fuzzy-logic stage}

In the fifth step, the stages were assembled using the Fuzzy Logic Toolbox and Simulink found in MATLAB R2018a. This forms the multi-stage fuzzy-logic architecture for reshoring decisions (Figure 2). The first stage 'Production resources' comprises the seven variables that concern either proximity or availability of resources. The variables 
are combined through a multiplexor to allow a shared input into the fuzzy inference system. The second stage 'Production capabilities' comprises the four variables connected to a multiplexor prior to the fuzzy inference system. As capabilities can be directly linked to achieved competitive priorities [3], each of the four variables also branches out towards the respective competitive priorities. Two of these variables (i.e., Volume flexibility, and Production mix flexibility) are combined using a mean operation before reaching the third stage. The third stage 'Competitive priorities' comprises the six variables. Finally, the outputs are combined and visualized using the scope operation.

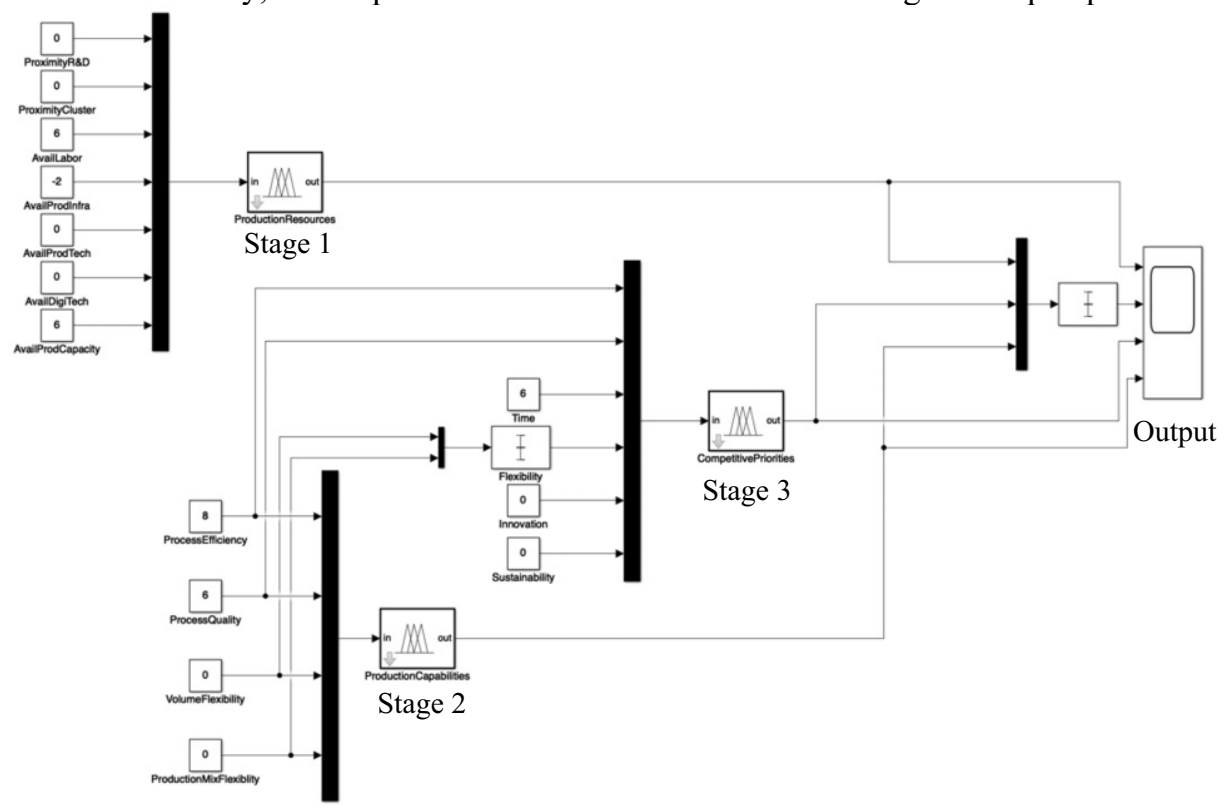

Figure 2. Multi-stage fuzzy-logic architecture for reshoring decisions.

\subsection{Develop reshoring scenarios}

In the sixth and final step, the multi-stage fuzzy-logic architecture was tested using ten different reshoring scenarios as input (Table 3). The first five scenarios were developed based on case study descriptions found in the reshoring literature [23,31]. The coding of the five scenarios was done by first, extracting the case descriptions to a spreadsheet and then, mapping a value $[-10,10]$ against the criteria, where -10 indicates a strong negative impact on a criterion while 10 indicates a strong positive impact. Scenarios 1, 2, and 3 were reshoring cases [23], whereas scenarios 4 and 5 were cases where firms did not reshore [31]. The variables that were not involved in the case description were marked with a zero. The last five scenarios were developed by the author to further test the model. Scenario 6 is a case when all values except 'Sustainability' and 'Availability of labor', are negative. This could be the case when the social pillar of sustainability is positively impacted at the expense of other reshoring criteria. Scenario 7 is a case when all the values except 'Availability of labor' and 'Volume flexibility' are positive. This could be the case when a company cannot cope with changing demands. Scenario 8 could be a case when the company is able to innovate by locating close to R\&D and industrial 
clusters, but, at the expense of flexibility-related criteria, while scenario 9 being the opposite of 8. Finally, scenario 10 is when all the values except 'Availability of labor' and 'Time' are positive. This could be a case when the company cannot find competent labor and has long lead times. The complete list of scenarios is shown in Table 3.

Table 3. Set of scenarios for testing the multi-stage fuzzy-logic model.

\begin{tabular}{|c|c|c|c|c|c|c|c|c|c|c|c|c|c|c|}
\hline 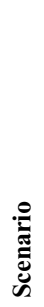 & 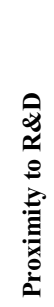 & 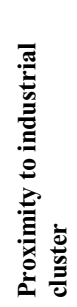 & 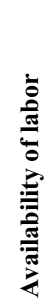 & 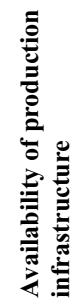 & 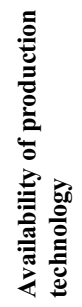 & 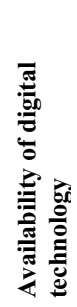 & 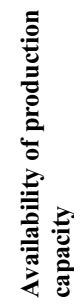 & 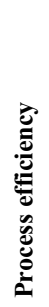 & 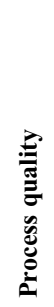 & 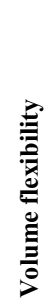 & 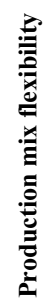 & 导 & 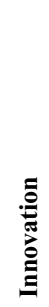 & 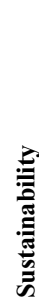 \\
\hline 1 & 0 & 0 & 6 & -2 & 0 & 0 & 6 & 8 & 6 & 0 & 0 & 6 & 0 & 0 \\
\hline 2 & 6 & 0 & 0 & 0 & 0 & 0 & 6 & 0 & 0 & 6 & 0 & 8 & 0 & 0 \\
\hline 3 & 4 & 0 & 4 & 4 & 6 & 0 & 0 & 0 & 4 & 8 & 4 & 0 & 0 & 0 \\
\hline 4 & 0 & 0 & -4 & 0 & 0 & 0 & -4 & 4 & -8 & 0 & 0 & -4 & 0 & 0 \\
\hline 5 & 0 & 0 & -4 & 0 & 0 & 0 & 0 & 4 & -4 & 0 & 0 & -4 & 0 & 0 \\
\hline 6 & -4 & -4 & 8 & -6 & -4 & -4 & -6 & -8 & -2 & -6 & -4 & -4 & -4 & 6 \\
\hline 7 & 6 & 4 & -2 & 6 & 4 & 8 & 2 & 4 & 10 & -2 & 6 & 4 & 8 & 4 \\
\hline 8 & 8 & 6 & 2 & -4 & 4 & 6 & -4 & -6 & 4 & -6 & -2 & -4 & 6 & 4 \\
\hline 9 & -2 & -4 & -2 & 4 & -2 & -2 & 2 & -2 & -2 & 4 & 6 & 4 & -6 & -4 \\
\hline 10 & 4 & 2 & -2 & 4 & 6 & 2 & 4 & 6 & 8 & 2 & 4 & -4 & 4 & 6 \\
\hline
\end{tabular}

\section{Results}

The results from the multi-stage fuzzy logic-based model when applying to the ten reshoring scenarios are shown in Table 4. The column 'output value' shows the output from the model in the range [-10,10], while the column 'decision recommendation' suggests whether a reshoring decision should be further evaluated or not (i.e., to exit the decision-making process). The decision recommendation from the first five scenarios can be compared to the actual result described in the case studies. It was found that four out of the five recommendations were consistent with the actual outcome. A conflict in recommendation was found in one of the scenarios (scenario 2) in which the output resulted in 0.00 , thereby recommending exiting the decision-making process while the outcome being described in the case study that the company had reshored. For scenarios 1 and 3, the model resulted in 3.53 and 3.22 respectively, which is a recommendation to further evaluate reshoring. On the other hand, for scenarios 4 and 5, the model recommends exiting the decision-making process. For scenarios 6-10, all the inputs were non-zeros values. For Scenario 6, the output from the model suggests a value of -6.26 , which gives a decision to exit the reshoring decision-making process. On the other hand, for Scenario 7, the output suggests a value of 6.08, which gives a decision to further evaluate the reshoring decision-making process. 
Table 4. Evaluation of reshoring scenarios.

\begin{tabular}{llll}
\hline Scenario & Output value & Decision recommendation & Outcome from case description \\
\hline $\mathbf{1}$ & 3.53 & Further evaluate $^{\mathrm{a}}$ & Reshored \\
\hline $\mathbf{2}$ & 0.00 & Exit $^{\mathrm{a}}$ & Reshored \\
\hline $\mathbf{3}$ & 3.22 & Further evaluate & Reshored \\
\hline $\mathbf{4}$ & 0.00 & Exit & Continued offshoring \\
\hline $\mathbf{5}$ & 0.00 & Exit & Continued offshoring \\
\hline $\mathbf{6}$ & -6.26 & Exit & n.a \\
\hline $\mathbf{7}$ & 6.08 & Further evaluate & n.a \\
\hline $\mathbf{8}$ & -1.6 & Exit & n.a \\
\hline $\mathbf{9}$ & -5.5 & Exit & n.a \\
\hline
\end{tabular}

${ }^{\mathrm{a} C o n f l i c t ~ i n ~ m o d e l ~ o u t p u t ~ a n d ~ o u t c o m e ~}$

\section{Concluding discussion}

There is a need to develop advanced tools to support the reshoring decision-making process $[4,26]$. As an answer, a transdisciplinary approach was adopted to develop a decision support tool. A transdisciplinary approach that combines knowledge from the engineering and operations management domains.

The developed multi-stage fuzzy-logic model simultaneously considered three groups of reshoring criteria. The developed model is relevant to reshoring decisions as different competencies could be involved in the decision-making process. The first group consisted of production resources, the second stage consisted of production capabilities, while the third stage consisted of overall competitive priorities. While previous research only considered competitive priorities for initial screening tools, this research includes a perspective of capabilities and resources which are relevant in an extended decisionmaking process. The ability of a multi-stage architecture to consider various groups of criteria make the decision-making process holistic. Furthermore, the developed decision support tool also indicates the output from each of the three stages in a digital format. This allows the decision-maker to understand the status of each stage while taking a decision.

The developed model contributes to the reshoring domain by providing a decision support tool that can be used in the decision-making process. The model is capable of branching the domains of engineering and operations management to solve a practically relevant problem in a transdisciplinary approach. For future research, the developed multi-stage fuzzy-logic model needs to be further tested on even more decision scenarios. Additional decision scenarios from published case study research needs to be explored to further test the model and by using different measures of accuracy. Furthermore, the developed multi-stage fuzzy-logic model needs to be tuned to avoid conflicting results.

\section{References}

[1] J. V. Gray, K. Skowronski, G. Esenduran, and M. J. Rungtusanatham, The Reshoring Phenomenon: What Supply Chain Academics Ought to know and Should Do, (in English), Journal of Supply Chain Management, 2013, Vol. 49, no. 2, pp. 27-33.

[2] C. Sansone, P. Hilletofth, and D. Eriksson, Critical operations capabilities for competitive manufacturing: a systematic review, Industrial Management \& Data Systems, 2017, Vol. 117, no. 5, pp. 801-837. 
[3] C. Sansone, P. Hilletofth, and D. Eriksson, Evaluation of critical operations capabilities for competitive manufacturing in a high-cost environment, Journal of Global Operations and Strategic Sourcing, 2020, Vol. 13 No. 3, pp. 229-250.

[4] P. Barbieri, F. Ciabuschi, L. Fratocchi, and M. Vignoli, What do we know about manufacturing reshoring?, Journal of Global Operations and Strategic Sourcing, 2018, Vol. 11, No. 1, pp. 79-122.

[5] J. V. Gray, G. Esenduran, M. J. Rungtusanatham, and K. Skowronski, Why in the world did they reshore? Examining small to medium-sized manufacturer decisions, Journal of Operations Management, 2017, Vol. 49, pp. 37-51.

[6] A. Boffelli, G. Orzes, and S. Dotti, "How to reshore": Some evidence from the apparel industry, IEEE Engineering Management Review, 2018, Vol. 46, No. 4, pp. 122-127.

[7] S. Grappi, S. Romani, and R. P. Bagozzi, Consumer stakeholder responses to reshoring strategies, (in English), Journal of the Academy of Marketing Science, 2015, Vol. 43, No. 4, pp. 453-471.

[8] M. Gylling, J. Heikkilä, K. Jussila, and M. Saarinen, Making decisions on offshore outsourcing and backshoring: A case study in the bicycle industry, International Journal of Production Economics, 2015, Vol. 162, pp. 92-100.

[9] P. Hilletofth, M. Sequeira, and A. Adlemo, Three novel fuzzy logic concepts applied to reshoring decision-making, Expert Systems with Applications, 2019, Vol. 126, pp. 133-143.

[10] M. Sequeira, Developing decision-support tools for evaluation of manufacturing reshoring decisions, Jönköping University, lic thesis, School of Engineering, 2020.

[11] P. Hilletofth, M. Sequeira, and W. Tate, Fuzzy-logic-based support tools for initial screening of manufacturing reshoring decisions, Industrial Management \& Data Systems, 2021, Vol. 121 No. 5, pp. 965-992.

[12] A. Moretto, A. S. Patrucco, and C. M. Harland, The dynamics of reshoring decisions and the role of purchasing, International Journal of Production Research, 2019, pp. 1-16.

[13] F.-L. Chung and J.-C. Duan, On multistage fuzzy neural network modeling, IEEE Transactions on fuzzy systems, 2000, Vol. 8, No. 2, pp. 125-142.

[14] L. Wang and Z. Liu, Data-driven product design evaluation method based on multi-stage artificial neural network, Applied Soft Computing, 2021, Vol. 103, 107117.

[15] K. Govindan, H. Mina, and B. Alavi, A decision support system for demand management in healthcare supply chains considering the epidemic outbreaks: A case study of coronavirus disease 2019 (COVID19), Transportation Research Part E: Logistics and Transportation Review, 2020, Vol. 138, 101967.

[16] N. Wognum, C. Bil, F. Elgh, M. Peruzzini, J. Stjepandić, and W. J. Verhagen, Transdisciplinary systems engineering: implications, challenges and research agenda, International Journal of Agile Systems and Management, 2019, Vol. 12, no. 1, pp. 58-89.

[17] L. Bals, J. F. Kirchoff, and K. Foerstl, Exploring the reshoring and insourcing decision making process: toward an agenda for future research, Operations Management Research, 2016, Vol. 9, No. 3-4, pp. 102116.

[18] B. Dachs, S. Kinkel, A. Jäger, and I. Palčič, Backshoring of production activities in European manufacturing, Journal of Purchasing and Supply Management, 2019, Vol. 25, No. 3, 100531.

[19] M. Johansson, J. Olhager, J. Heikkilä, and J. Stentoft, Offshoring versus backshoring: Empirically derived bundles of relocation drivers, and their relationship with benefits, Journal of Purchasing and Supply Management, 2019, Vol. 25, No. 3, 100509.

[20] M. Sequeira, P. Hilletofth, and A. Adlemo, AHP-based support tools for initial screening of manufacturing reshoring decisions, Journal of Global Operations and Strategic Sourcing, 2021, https://doi.org/10.1108/JGOSS-07-2020-0037.

[21] A. Ancarani, C. Di Mauro, and F. Mascali, Backshoring strategy and the adoption of Industry 4.0: Evidence from Europe, Journal of World Business, 2019, Vol. 54, No. 4, pp. 360-371.

[22] B. Dachs, S. Kinkel, and A. Jäger, Bringing it all back home? Backshoring of manufacturing activities and the adoption of Industry 4.0 technologies, Journal of World Business, 2019, Vol. 54, No. 6, 101017.

[23] G. Engström, K. Sollander, P. Hilletofth, and D. Eriksson, Reshoring drivers and barriers in the Swedish manufacturing industry, Journal of Global Operations and Strategic Sourcing, 2018, Vol. 11, No. 2, pp. 174-201.

[24] B. B. Nujen, D. E. Mwesiumo, H. Solli-Sæther, A. B. Slyngstad, and L. L. Halse, Backshoring readiness, Journal of Global Operations and Strategic Sourcing, 2019, Vol. 12 No. 1, pp. 172-195.

[25] L. Fratocchi and C. Di Stefano, Does sustainability matter for reshoring strategies? A literature review, Journal of Global Operations and Strategic Sourcing, 2019, Vol. 12 No. 3, pp. 449-476.

[26] J. Stentoft, O. S. Mikkelsen, and J. K. Jensen, Flexicurity and relocation of manufacturing, Operations Management Research, 2016, Vol. 9, No. 3-4, pp. 133-144.

[27] S. Kinkel, Trends in production relocation and backshoring activities: changing patterns in the course of the global economic crisis, International Journal of Operations \& Production Management, 2012, Vol. 32, No. 6, pp. 696-720. 
[28] L.-E. Gadde and P. Jonsson, Future changes in sourcing patterns: 2025 outlook for the Swedish textile industry, Journal of Purchasing and Supply Management, 2019, Vol. 25, No. 3, 100526.

[29] L. Zadeh, The concept of a linguistic variable and its application to approximate reasoning-I, Information sciences, 1975, Vol. 8, No. 3, pp. 199-249.

[30] L. M. Ellram, W. L. Tate, and K. J. Petersen, Offshoring and reshoring: an update on the manufacturing location decision, Journal of Supply Chain Management, 2013, Vol. 49, No. 2, pp. 14-22.

[31] C. Joubioux and E. Vanpoucke, Towards right-shoring: a framework for off-and re-shoring decision making, Operations Management Research, 2016, Vol. 9, No. 3-4, pp. 117-132. 